APJES I-I (2013) 15-19

\title{
Neutron Shielding Properties Of Concrete With Boron And Boron Containing Mineral
}

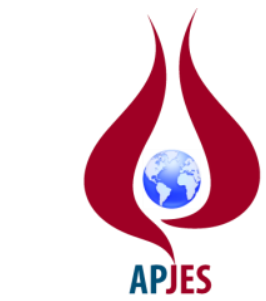

Academic Platform Journal of Engineering and Science

*Corresponding author: Address: Istanbul Commerce University, Faculty of Arts and Science, Halic University, Istanbul, 34394, TURKEY. E-mail address: salimorak@ @otmail.com

\begin{abstract}
Concrete is a material which widely used as a neutron shielding and in building construction such as nuclear power stations, particle accelerators and medical hospitals. Concrete is very significant for neutron shielding, because of concrete is contain of some elements (hydrogen, iron etc.) to moderate the fast neutrons which are very penetrative. Boron increases the neutron shielding effectiveness of concretes, since the boron isotope ${ }^{10} \mathrm{~B}$ has a high capture cross-section for thermal neutrons (over 3800 barns). Boron can be added to concrete different ways such as addition of boron to the water used in concrete or addition of boron containing natural minerals.

Neutron shielding capabilities of the sample can be described by total neutron macroscopic cross-section $\left(\Sigma_{t}\right)$. It is the sum of the cross-sections for all the neutron-interaction processes such as the elastic and inelastic scattering reactions and neutron capture reactions $((\mathrm{n}, \alpha),(\mathrm{n}, \gamma))$.

In this study, the effect of addition boron and colemanite on the total macroscopic cross section of Portland concrete was investigated. Colemanite is one of the most important boron minerals and Turkey has the largest colemanite reserves in the world. Its compact formula is $\mathrm{Ca}_{2} \mathrm{~B}_{6} \mathrm{O}_{11} \cdot 5\left(\mathrm{H}_{2} \mathrm{O}\right)$. Also, colemanite can be used for shielding fast and thermal neutrons, since it includes both of hydrate and boron.

In experiments, ${ }^{241} \mathrm{Am}-\mathrm{Be}$ neutron source with $74 \mathrm{GBq}$ activity were used in. Average neutron energy of this source is approximately $4.5 \mathrm{MeV} . \mathrm{BF}_{3}$ detector with diameter $2.54 \mathrm{~cm}$ and length of $28 \mathrm{~cm}$ was used for counting neutrons. Also, Monte Carlo simulations were done for comparison of macroscopic cross section experimental results. Besides total macroscopic cross sections, absorbed doses and deposited energies by low energy neutron interactions were calculated using MCNP4C2 Monte Carlo code. The results have been compared with the standard shielding material of paraffin. Also, half-value layer (HVL) and tenthvalue layer (TVL) were calculated and compared.
\end{abstract}

Keywords: Neutron Shielding, MCNP Monte Carlo Code, Total Macroscopic Cross Section, HVL, TVL 


\section{Introduction}

Concrete is the most generally used shield material as it is low-cost and adjustable for any construction design (Singh et al., 2008; Ne ville, 1989). A lot of studies about neutron shielding by using concrete have been done until now (Jaeger et al., 1975,; Kaplan, 1989; Ibrahim and Rashed, 1998, Akkurt et al., 2005; Kharita et al., 2008). Some of researchers have tried to increase of shielding effectiveness of concrete by adding boron compounds such as boric acid, borax etc. (Yarar et al., 1994, Kharita et al., 2011). One of the most important boron minerals is colemanite and its compact formula is $\mathrm{Ca}_{2} \mathrm{~B}_{6} \mathrm{O}_{11} \cdot 5\left(\mathrm{H}_{2} \mathrm{O}\right)$. Also, colemanite can be used for shielding fast and thermal neutrons, since it is include both of hydrate and boron.

In this study, we have aimed to measure experimental and simulate total neutron macroscopic cross sections for boron and colemanite loaded Portland concrete. Additionally, absorbed doses and deposited energy values have been determined by Monte Carlo simulations.

\section{Experiments and Monte Carlo Simulations}

Neutron absorption experiments were done for $20 \%$ boron and colemanite mineral loaded Portland concrete. For this purpose, ten samples have been prepared at $2.3 \mathrm{~cm}$ thickness for each additive. Experiments have been performed by ${ }^{241} \mathrm{Am}-\mathrm{Be}$ neutron source with $74 \mathrm{GBq}$ activity. Average and maximum neutron energies of this source are 4.5 and 12 $\mathrm{MeV}$, respectively. Transmitted neutron particles have been measured by $\mathrm{BF}_{3}$ detector with diameter $2.54 \mathrm{~cm}$ and length of $28 \mathrm{~cm}$. Experimental set up used in present study is shown in Figure 1.

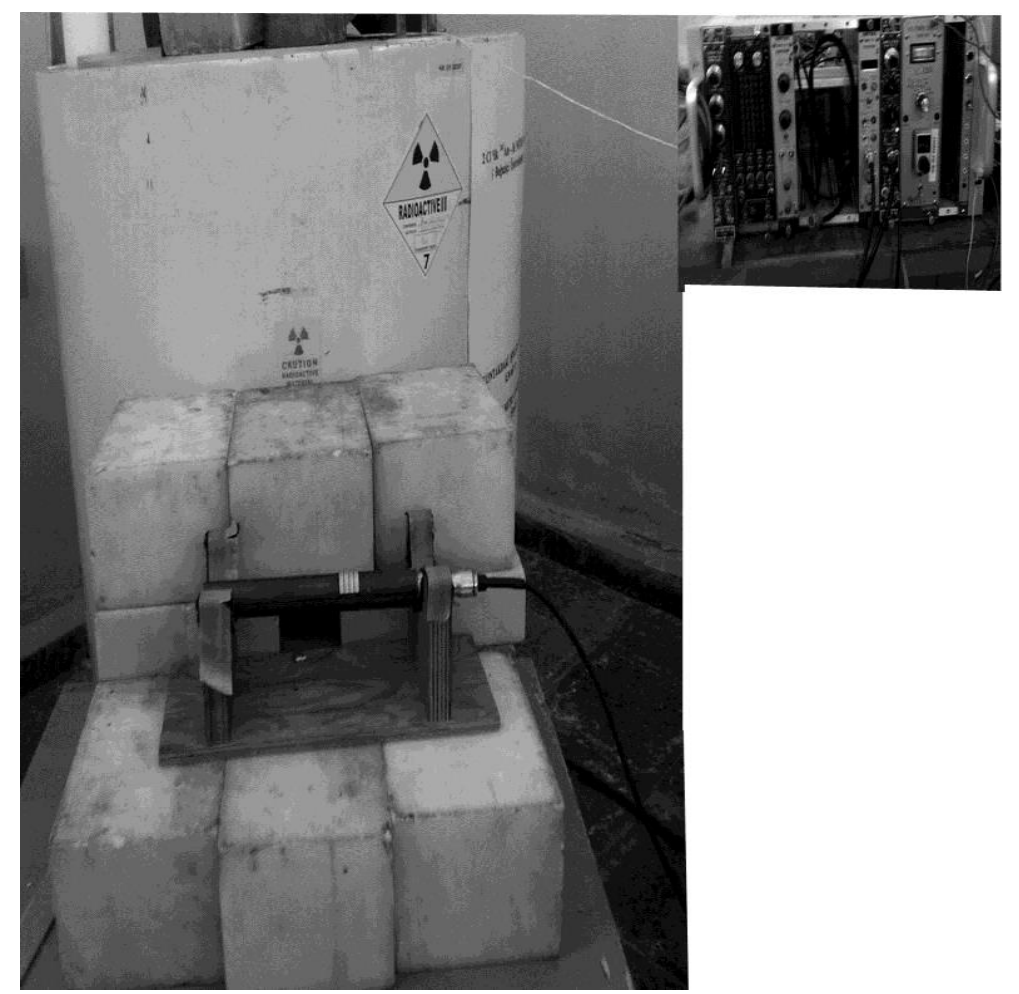

Figure 1. Experimental set up

MCNP of version 4C2 code, a well known Monte Carlo neutron-particle transport code, was used to simulate the system (Briesmeister, 2000). The neutron macroscopic cross section has been simulated from MCNP code for neutron particles having 4.5 MeV average neutron energy. The number of neutrons crossing front and back sides of the sample was determined using a surface current tally. Absorbed dose and deposited neutron energies by neutron interactions have been simulated by using power law built in function $p(x)=c|x|^{a}$ for the ${ }^{241} \mathrm{Am}-\mathrm{Be}$ neutron source. Chemical compositions and elemental mass ratios of samples which are used in simulations compared to typical Portland concrete (PC) have been listed in Table 1. 
Salim Orak / APJES I-I (2013) 15-19

Table 1. Chemical compositions and elemental mass ratios of samples

\begin{tabular}{|l|c|c|c|}
\hline & $\begin{array}{c}\text { Portland } \\
\text { concrete } \\
(2.35 \\
\left.\mathrm{g} / \mathrm{cm}^{3}\right)\end{array}$ & $\begin{array}{c}20 \% \text { boron } \\
\text { loaded PC } \\
\left(1.59 \mathrm{~g} / \mathrm{cm}^{3}\right)\end{array}$ & $\begin{array}{c}20 \% \text { colemanite } \\
\text { loaded PC }(1.56 \\
\left.\mathrm{g} / \mathrm{cm}^{3}\right)\end{array}$ \\
\hline Hydrogen & 0.0056 & 0.0045 & 0.0094 \\
\hline Oxygen & 0.4996 & 0.3997 & 0.5242 \\
\hline Sodium & 0.0171 & 0.0137 & 0.0137 \\
\hline Magnesium & 0.0024 & 0.0019 & 0.0019 \\
\hline Aluminum & 0.0458 & 0.0366 & 0.0366 \\
\hline Silicon & 0.3150 & 0.2520 & 0.2520 \\
\hline Potassium & 0.0191 & 0.0153 & 0.0153 \\
\hline Calcium & 0.0831 & 0.0665 & 0.1055 \\
\hline Iron & 0.0123 & 0.0098 & 0.0098 \\
\hline Boron-10 & - & 0.0398 & 0.0062 \\
\hline Boron-11 & - & 0.1602 & 0.0253 \\
\hline
\end{tabular}

\section{Results and Conclusion}

The macroscopic cross-section $\Sigma$ is important factor to determine neutron shielding property of samples. $\Sigma_{\text {tot }}$ is the probability per unit path length that any type of interaction may occur. It is conventional to express this probability in terms of the cross-section $\sigma_{\mathrm{n}}$ per nucleus for each type of interaction. When multiplied by the number of nuclei $N$ per unit volume, the cross-section $\sigma_{\mathrm{n}}$ is converted into the macroscopic cross-section $\Sigma_{\text {tot }}$, where

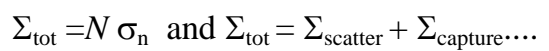

Total macroscopic cross section values were calculated from Beer-Lambert Law:

$$
I(x)=I_{o} e^{-\Sigma x}
$$

where $I_{o}$ is some known value of beam intensity, at a material thickness of $\mathrm{x}=0$ (T. Korkut et al., 2010).

The measured and simulated values of total macroscopic cross sections of samples are shown in Table 2. As it can be seen in this table, borated concrete is better neutron shielding material than colemanite loaded concrete. Also transmission values as a function of the sample thickness were shown in figure 2 and 3 . As can be seen from these figures, transmission values were decreased exponentially with increasing the sample thickness. Also experimental and simulation half value layer and tenth value layer (TVL) values of paraffin wax, boron loaded and colemanite loaded Portland concrete for $4.5 \mathrm{MeV}$ neutrons were shown in Table 3 and 4

Table 2. Total macroscopic cross sections

\begin{tabular}{|l|c|c|}
\cline { 2 - 3 } \multicolumn{1}{c|}{} & Experiment & Simulation \\
\hline Sample & $\Sigma_{\mathrm{t}}\left(\mathrm{cm}^{-1}\right)$ & $\Sigma_{\mathrm{t}}\left(\mathrm{cm}^{-1}\right)$ \\
\hline PC+20\% Boron & 0.128 & 0.127 \\
\hline PC+20\% Colemanite & 0.119 & 0.121 \\
\hline
\end{tabular}

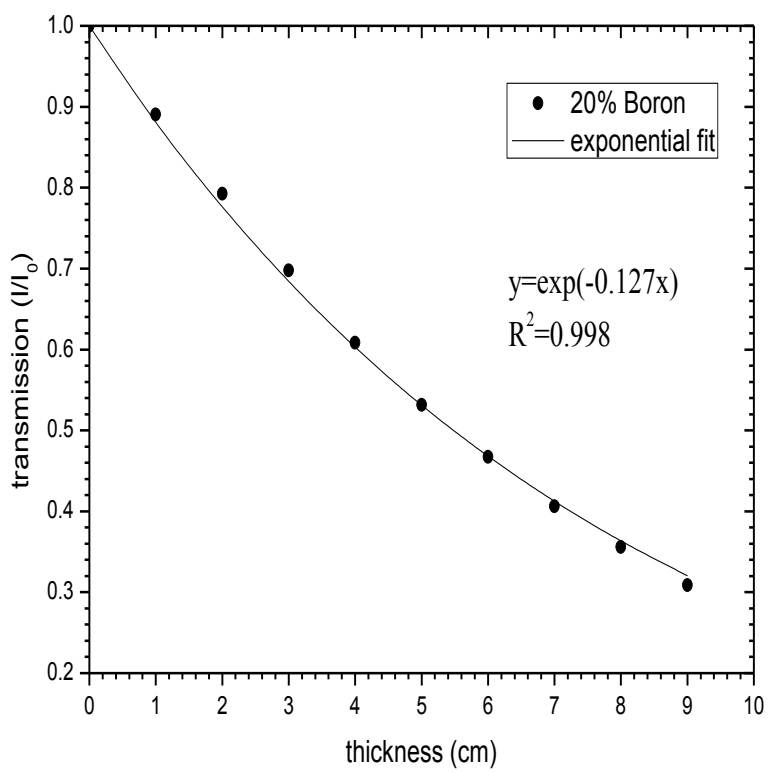

Figure 2. Transmission values as a function of borated Portland concrete sample thickness 
Salim Orak / APJES I-I (2013) 15-19

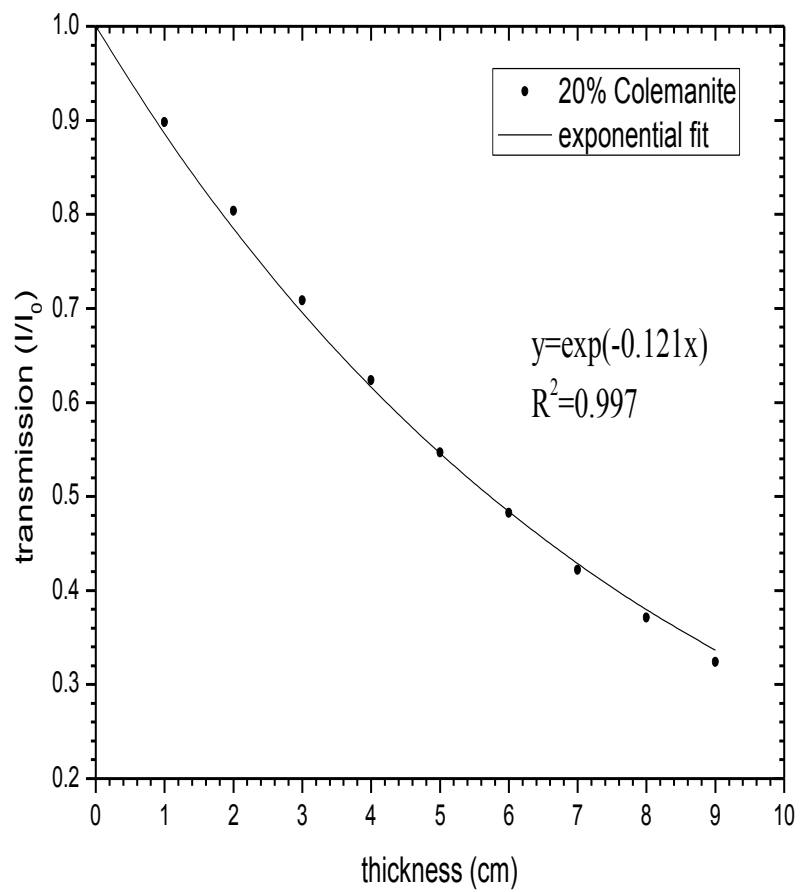

Figure 3. Transmission values as a function of colemanite loaded Portland concrete sample thickness

Table 3. HVL values of samples

\begin{tabular}{|l|c|c|}
\hline \multicolumn{3}{c|}{ Half value layer $(\mathrm{cm})$} \\
\hline Sample & Experiment & Simulation \\
\hline Parafin wax & $3.96^{*}$ & 3.97 \\
\hline PC+20\% Boron & 5.41 & 5.47 \\
\hline PC+20\% Colemanite & 5.82 & 5.72 \\
\hline
\end{tabular}

*From Desdin and Ceballos(2000)
Table 4. TVL values of samples

\begin{tabular}{|l|c|c|}
\cline { 2 - 3 } \multicolumn{1}{c|}{} & \multicolumn{2}{c|}{ Tenth value layer $(\mathrm{cm})$} \\
\hline Sample & Experiment & Simulation \\
\hline PC+20\%boron & 17.99 & 18.20 \\
\hline PC+20\%colemanite & 19.35 & 19.03 \\
\hline
\end{tabular}

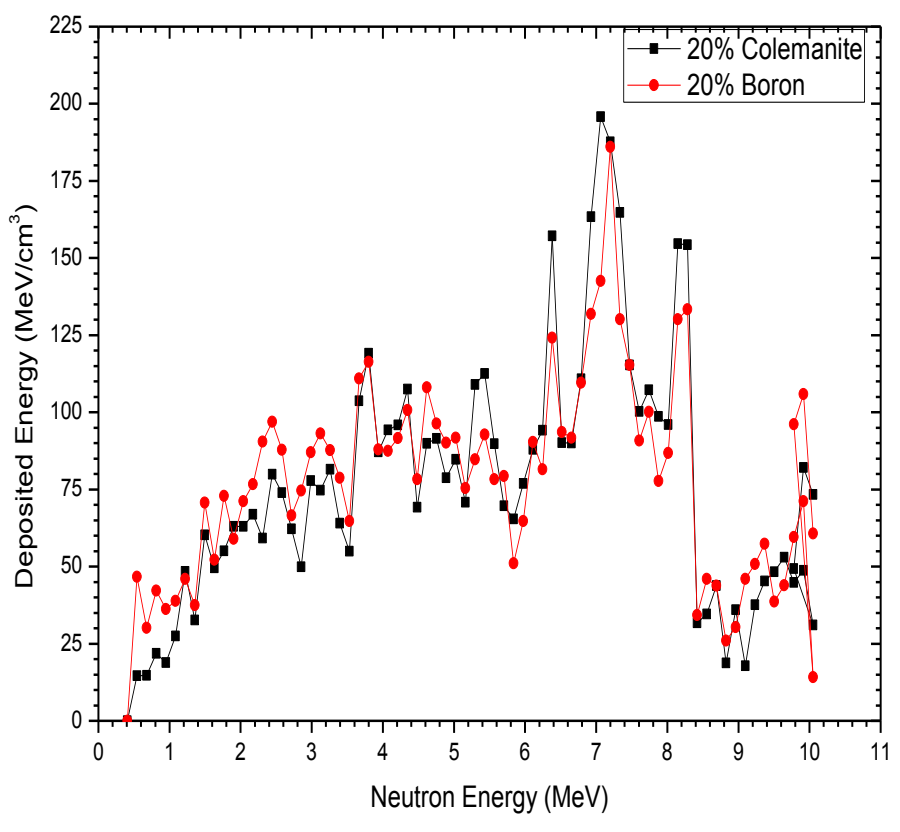

Figure 4. Deposited energy variations as a function of neutron energy 
Salim Orak / APJES I-I (2013) 15-19

Table 5. Absorbed dose values

\begin{tabular}{|l|c|}
\hline Sample & $\begin{array}{c}\text { Absorbed Dose } \\
(\mu \mathrm{Gy} / \mathrm{h})\end{array}$ \\
\hline PC+20\% colemanite & $2.31 \times 10^{3}$ \\
\hline PC+20\% boron & $2.43 \times 10^{3}$ \\
\hline
\end{tabular}

Total absorbed dose rate for samples was calculated via MCNP code. According to simulation results, $20 \%$ boron loaded Portland concrete has higher total absorption dose rate than $20 \%$ colemanite loaded concrete. Deposited energy values per unit volume as a function of neutron energy were shown in Figure 4. The simulation results confirm that borated Portland concrete sample has higher attenuation effects for lower neutron energy from 3.5 MeV. Maximum deposited energy appears 7-8 MeV energy neutron region.

When it is compared the experimental and simulation results for boron and colemanite added concrete, it is clear that addition of boron increases the effectiveness of neutron shielding than the others. Although HVL value of borated concretes are not as good as value of paraffin wax, these materials can be used for building walls of nuclear power stations, medical hospitals or as a moderator nuclear investigation centers and particle accelerators.

\section{References}

[1] Akkurt, I., Basyigit, C., Kilincarslan, S., Mavi, B., 2005. The shielding of gamma rays by concretes produced with barite. Progress in Nuclear Energy 46, 1-11.

[2] Briesmeister, J.F., 2000. MCNP - A general Monte Carlo n-particle transport code, version 4C, LA-13079-M, Los Alamos, USA.

[3] Desdin, L., Ceballos, C., 2000. Neutron reflection method for the fast estimation of neutron removal cross section in hydrogenous materials. J. Radioanal. Nucl. Chem. 243 (3), 835-837.
[4] Ibrahim, M.A., Rashed, R.A., 1998. Deduction of some neutron shielding parameters for different types of concrete made from local materials.Nuclear Science Journal 35 (4),245-250.

[5] Jaeger, R.G., Blizard, E.P., Chilton, A.B., Grotenhuis, M., Hoenig, A., Jaeger, Th.A, Eisenlohr, H.H., 1975. Engineering compendium on radiation shielding. In: Shielding Materials, vol. II. Springer-Verlag.

[6] Kharita, M.H., Takeyeddin, M., Alnassar, M., Yousef, S., 2008. Development of special radiation shielding concretes using natural local materials and evaluation of their shielding characteristics. Progress in Nuclear Energy 50, 33-36.

[7] Kharita, M.H., Yousef, S., Alnassar, M., 2011. Review on the addition of boron compounds to radiation shielding concrete. Progress in Nuclear Energy 53, 207-211

[8] Kaplan, M.F., 1989. Concrete Radiation Shielding. Longman Scientific \& Technical,England.

[9] Korkut, T., Karabulut, A., Budak, G., Korkut, H., 2010. Investigation of fast neutron shielding characteristics depending on boron percentages of $\mathrm{MgB}_{2}, \mathrm{NaBH}_{4}$ and $\mathrm{KBH}_{4}$. J Radioanal Nucl Chem. 286, 61-65

[10] Neville, A.M., 1989. Properties of Concrete. ELBS.

[11] Singh, K.J., Singh, N., Kaundal, R.S., Singh, K., 2008. Gamma-ray shielding and structural properties of $\mathrm{PbO}-\mathrm{SiO} 2$ glasses. Nuclear Instruments and Methods in Physics Research B 266, 944-948 (ELSEVIER).

[12] Yarar Y, Bayülgen A (1994). Investigation of neutron shielding efficiency and radioactivity of concrete shields containing colemanite. J. Nucl. Mater. (212-215): 17201723 